\title{
Patient-specific finite element model of the hip muscles and bones
}

\author{
Erwan Jolivet*,** — Jean-Denis Laredo** \\ Dominique Bonneau* — Wafa Skalli* \\ * Laboratoire de biomécanique, ENSAM Paris CNRS UMR 8005 \\ 151 boulevard de l'hôpital, F-75011 Paris \\ wafa.skalli@paris.ensam.fr \\ ** Laboratoire de radiologie expérimentale, Paris CNRS UMR 7052 \\ Faculté de médecine Lariboisière Saint-louis \\ 10 avenue de verdun, F-75010 Paris \\ jean-denis.laredo@lrb.aphp.fr
}

\begin{abstract}
Hip fractures are largely considered as a major health-care problem. Several patientspecific finite element models of the isolated femur are proposed to evaluate fracture risk. However, because of their role in femur stress distribution, soft tissue covering the hip should also be considered. Such modeling is particularly complex and major difficulties are related to volumic muscle mesh generation, to specific muscles constitutive equations and numerous contacts within the structure. A method was based on deformation of a parameterized muscle mesh was proposed to get rapidly a patient-specific non distorted mesh. Based in this mesh, finite element model included bones and soft tissues, with surface contact elements between components. Hyperelastic constitutive equations, with hypothesis of incompressibility and isotropy were used to model soft tissue mechanical behavior. Preliminary simulation with quasistatic lateral compression was performed to verify the coherence of the model's response.

RÉSUMÉ. Les fractures de l'extrémité supérieure du fémur représentent un problème de santé publique. Plusieurs modèles personnalisés du fémur proximal sont proposés dans la littérature. Cependant, les tissus mous recouvrant la hanche doivent être considérés du fait de leur rôle dans la distribution des contraintes dans le fémur. De tels modèles sont complexes et les difficultés concernent le maillage des muscles, la détermination d'équations constitutives pour les tissus mous et la gestion de nombreux contacts. Une méthode s'appuyant sur une déformation d'un maillage paramétré du muscle est proposée afin d'obtenir rapidement un maillage non distordu des muscles considérés. Le modèle intègre ainsi les structures osseuses et les tissus mous avec une gestion des surfaces de contact entre les composants. Les lois matériaux utilisées pour les tissus mous sont de type hyperélastique incompressible isotrope. La première évaluation de ce modèle, soumis à une compression latérale en quasi-statique, a permis de vérifier la cohérence du comportement du modèle.
\end{abstract}

KEYWORDS: finite element, muscle, soft tissue, hip fracture.

MOTS-CLÉS: éléments finis, muscle, tissus mous, fracture de hanche.

DOI:10.3166/EJCM.18.117-129 (c) 2009 Lavoisier, Paris

EJCM - 18/2009. Numerical models in biomechanics, pages 117 to 129 


\section{Introduction}

According to World Health Organization, osteoporosis is a disease involving a diminution of bone mass associated to a deterioration of bone micro-architecture, leading to an increase of the fracture risk. Osteoporotic fracture of the proximal femur is a major health problem over the world: about $20 \%$ of fractured subject die during the first year following its fracture and only $40 \%$ of patients recover a total autonomy two years after (Dreux et al., 2001). The cost of osteoporosis (30 billions euros during the year 2000 in Europe alone) is expected to double until 2050 (International Osteoporosis Foundation, 2004), and considering the high cost of any preventive strategy, the accurate identification of patients with a high fracture risk is essential.

Currently, bone density measurement with a Dual Xray Absorptiometry (DXA) is the clinical standard protocol for diagnosis and prevention of osteoporosis. However this exam does not enable to identify all patients who will undergo a hip fracture (De Laet et al., 1997; Schuit et al., 2004). Indeed, this measurement refers to bone material whereas femur geometry has also its own importance as for any mechanical structure.

While finite element model is widely used to analyze mechanical structure, the complexity of human structures and their variability make difficult their application in clinical routine. However, such modeling is efficient to study bone fracture such as osteoporotic fracture. Indeed, a finite element model takes account for material characteristics and specific geometry of the structure. Using finite element models of the proximal femur, it is possible to consider the material and the specific geometry of the femur for each patient and to evaluate the fracture load of the isolated structure (Cody et al., 2000; Duchemin et al., 2007b; Keyak et al., 1998). Majority of hip fracture result of a fall of the subject but only 1\% of fall cause hip fracture (Cummings et al., 1994). The fall from standing height is associated with an energy from 40 to 500 $\mathrm{J}$ (Hayes et al., 1993). This amount of energy is about ten times the energy needed to fracture the proximal femur emphasizing the importance of the presence of soft tissue over the hip (Bouxsein et al., 2007; Lotz et al., 1990). However patient-specific dynamic model of the hip including bone and soft tissue is extremely complex.

Even when considering at a first step quasi-static muscular model, major difficulties concern volumic muscle meshing from medical images and the definition of an appropriate constitutive equation muscle mechanical behavior. Usually, muscle volume and its associated mesh are generated from manual contouring on many medical images (CT-scan or, IRM), but this process is long and tedious (Behr et al., 2006; Blemker et al., 2006; Jaegers et al., 1992; van Donkelaar et al., 1996).

Thus, the goal of this present study is to propose a patient-specific finite element model of the hip including soft tissues and bones. First, a method is proposed to generate a non distorted volumic mesh of muscles from CT-scan acquisitions. This mesh was the base for a finite element model that differentiated pelvic bone, proximal femur, glutei muscles and subcutaneous fat. Then a preliminary evaluation with quasi-static lateral 
compression was performed to establish the feasibility of an evaluation of potentials risk factors for hip fracture associated with soft tissue using a patient-specific modeling.

\section{Material and Method}

CT scan axial acquisitions covering the pelvis and hip joint were used in this study to obtain the geometry of bone and soft tissue structures. Slice thickness was $5 \mathrm{~mm}$ with an inter-slices gap of $5 \mathrm{~mm}$. The reconstruction diameter was $460 \mathrm{~mm}$, corresponding to a pixel resolution of 0.90 by $0.90 \mathrm{~mm}^{2}$. Ten subjects were considered ( 5 males and 5 females, age range 25-77 years old, Body mass index range 19.8-35.9 kg. $\mathrm{m}^{-2}$ ) and were meshed. A simulation of a quasi-static lateral compression was performed on one representative subject. This subject was a female, 37 years old and a body mass index equal to $19.8 \mathrm{Kg} \cdot \mathrm{m}^{-2}$. The protocol was approved by the ethical committee of our institution and the subject gave their informed written consent before participation.

Patient-specific modeling and mesh must take into account for large inter-individual variation of anatomical structures geometries. For that, the Laboratory of Biomechanics of ENSAM have developed methods of generation of anatomical structures meshes based on a definition of a parametric mesh (Duchemin et al., 2007b; Lavaste et al., 1992). This mesh was constructed from geometric primitives adapted to represent the considered anatomical structure. Then the parametric mesh was deformed to fit geometric data collected on medical images to obtain a patient-specific mesh. Specific method for muscles geometry and muscles mesh generation is detailed hereafter.

\subsection{Bone}

Because pelvis was only considered as the support for muscle's insertions and femoral head reception, it was modeled as a rigid body. Pelvic mesh was generated from CT-scan images with shell elements and based on a three dimensional reconstruction of bone obtained by segmentation of bone on CT-scan slices using a threshold of 150 Hounsfield units. A generic mesh was deformed to fit these segmented data (Besnault et al., 1999; Lafage et al., 2001).

Femur was semi-automatically segmented on CT-scan axial slices. The volumic hexahedral mesh of the proximal femur from this segmented volume data was generated using a generic definition of the mesh. The mesh was constituted of hexahedral linear isoparametric elements and was deformed by projection of the border nodes on the isosurface defining by the segmented data according to the method used by Duchemin et al. (Duchemin et al., 2007b). For a first estimation of muscle and soft tissue effect, the cortical bone was represented by one layer of elements and thickness profile was fixed to the mean repartition of cortical bone determined from the analysis of CT-scan data on forty femurs of a previous study (Duchemin et al., 2007b). 
Bone material was considered linear and isotropic for cortical bone as well as for spongious bone (Couteau et al., 1998). Young modulus and Poisson's ratios were detailed in Table 1.

\subsection{Soft tissue}

\subsubsection{Geometry and mesh}

Muscles that contribute to energy absorption were included in the model, i.e. gluteus maximus, medius and minimus muscles (Figure 1). They were differentiated in the 3D mesh constructed with a method based on a predefined parametric mesh. This parametric mesh was generated from muscle contour on a reduced number of slices (6 contours for gluteus maximus muscle and 4 contours for gluteus medius and gluteus minimus muscles). The digitized contour was modeled as a geometric primitive: an ellipse whose center corresponded to the barycenter of the contour, ellipse's orientation on image was determined with the local inertial frame of muscular contour and axes length from contour dimensions. A spline interpolation of these descriptive ellipse parameters was realized along the direction of CT-scan acquisition. In this way, an ellipse was constructed for each image of the acquisition between the first and the last slices where the muscle was present. The number of ellipse generated was roughly from 30 to 45 depends on muscle.

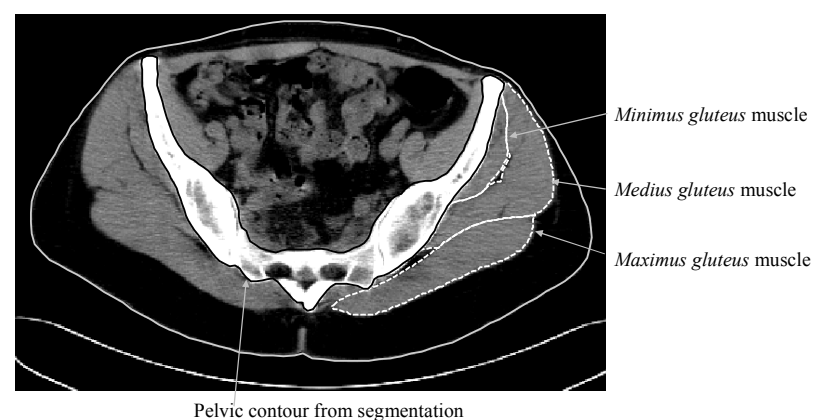

Figure 1. Glutei muscles contours on CT-scan axial slices and pelvic contour from segmentation

To construct the $3 \mathrm{D}$ parametric mesh, a $2 \mathrm{D}$ square mesh of 16 elements with 20 border nodes was associated with each ellipse modeled. Then, planar meshes were connected together to generate the parametric hexahedral mesh of muscle.

Finally, the parametric mesh was deformed with a non linear transformation function defining by points on muscle contours and their corresponding border nodes (Lafage et al., 2001; Trochu, 1993). Applying this transformation function on the 
whole mesh, hexahedral mesh fit to digitalized muscle contours on the reduced number of slices at the end of the process. Muscle elements were linear and isoparametric with mixed pressure/displacement formulation. Once all muscle meshes were realized, an algorithm was applied to rectify interface of contacts between model's components. Nodes, which were detected within the external neighboring mesh, were retro-projected on the surface of this muscle in order to obtain adjusted contact surface between muscles and between muscles and bones (Figure 2).

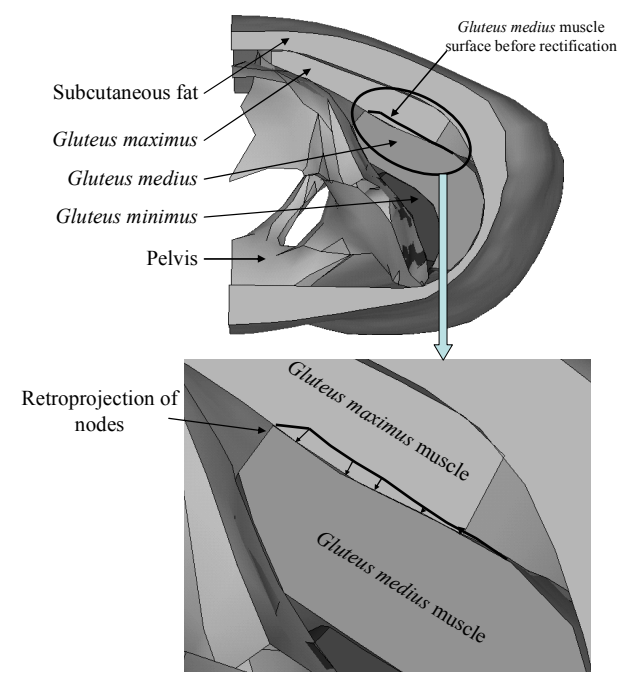

Figure 2. Nodes which were detected inside the external component mesh were retroprojected on the surface. In this example, nodes of gluteus medius muscle in penetration were projected on the surface of gluteus maximus muscle

The skin was automatically segmented on CT-scan axial slices. From these data, a surfacic mesh with three nodes shell was generated. The thickness was fixed to $1 \mathrm{~mm}$ (Diridollou et al., 2000; Hendriks et al., 2003). Shell elements had only membrane stiffness with three degrees of freedom in translation at each node.

In order to generate subcutaneous fat mesh, the convex hull of the bone and muscle meshes was computed. Hexahedral mesh was realized by horizontal projection of the skin's nodes on the convex hull. Five element layers were generated by linear interpolation between skin's nodes and their projection. The internal nodes were smoothed with a discret laplacian filter to obtain a regular mesh with minimal distortion of the element and acceptable aspect ratio. Fat elements were linear and isoparametric with mixed pressure/displacement formulation.

Finally, tendons were added manually on distal extremities of the three glutei muscles. They were modeled with slack cable element, with only a tension action (no 
stiffness in compression). Tendon insertions on proximal femur were established under anatomical considerations.

\subsubsection{Material properties}

Mechanical behavior of soft tissue was considered isotropic, hyperelastic and quasi-incompressible. A Mooney-Rivlin constitutive material law was used. The strain energy function is formulated as follow:

$$
\mathrm{W}=\mathrm{C}_{10}\left(\mathrm{I}_{1}-3\right)+\mathrm{C}_{01}\left(\mathrm{I}_{2}-3\right)+0.5 * \mathrm{~K} *\left(\mathrm{~J}^{2}-1\right)
$$

$I_{1}$ and $I_{2}$ are the invariants of the right Cauchy deformation tensor. $K$ is the bulk modulus and the last term of Mooney-Rivlin constitutive material law ensure the quasi incompressibility of the material with $\mathrm{J}$ the third invariant of the deformation tensor that represents the volume change. The value of material constants were determined from compression test by Untaroiu et al. on human muscle and fat samples (Untaroiu et al., 2005). Material constants of the Mooney-Rivlin law are detailed for muscle tissue and subcutaneous fat in Table 1. Skin was considered linear and isotropic and its young modulus and Poisson's ratio are specified in Table 1. Tendon material was also supposed to be linear and isotropic, Young modulus and Poisson's ratio are specified in Table 1.

Table 1. Material properties: Young modulus and Poisson's ratio for elastic material, coefficient and bulk modulus of the Mooney-Rivlin constitutive law used for muscle and subcutaneous fat

\begin{tabular}{|l|c|c|c|c|c|}
\hline \multirow{2}{*}{ Tissue } & \multicolumn{2}{|c|}{ Elastic Material } & \multicolumn{3}{c|}{ Hyperelastic Mooney-Rivlin } \\
\cline { 2 - 6 } & $\begin{array}{c}\text { Young Modulus } \\
\text { (Gpa) }\end{array}$ & Poisson's ratio & $\begin{array}{c}\mathrm{C}_{10} \\
(\mathrm{kPa})\end{array}$ & $\begin{array}{c}\mathrm{C}_{01} \\
(\mathrm{kPa})\end{array}$ & $\begin{array}{c}\mathrm{K} \\
(\mathrm{Mpa})\end{array}$ \\
\hline $\begin{array}{l}\text { Cortical femur } \\
\text { bone }\end{array}$ & 17000 & 0,3 & & & \\
\hline $\begin{array}{l}\text { Spongious } \\
\text { femoral bone }\end{array}$ & 900 & 0,3 & & & \\
\hline Muscle & & & 0,12 & 0,25 & 20 \\
\hline $\begin{array}{l}\text { Subcutaneus } \\
\text { fat }\end{array}$ & 1 & 0,45 & & & 20,28 \\
\hline Skin & 12 & 0,3 & & & \\
\hline Tendon & & & 0,19 & & \\
\hline
\end{tabular}

\subsection{Simulation}

Meshes were generated with specific application developed on Matlab V7.0.4 SP2 software. Then meshes were transferred on Ansys V11.0 application for simulation.

First, mesh quality was analyzed. Criteria of aspect ratio, Jacobian ratio, warping factor, parallel deviation ands maximal angle corner were analyzed for all elements. 
Tied contact were defined between femoral head and the cotyle, between iliac crest and each gluteus muscle, between gluteus medius and gluteus minimus muscles, between gluteus maximums muscle and subcutaneous fat and between gluteus medius muscle and subcutaneous fat. Sliding contact, without friction, was defined between glutei muscles and femur, between subcutaneous fat and femur and finally between gluteus maximus muscle and gluteus medius muscle. All those contacts were represented using node to surface contact elements and defined symmetrically An augmented Lagrangian contact algorithm was used (an iterative series of penalty method).

In order to reduce the computer time, only the left-half of the mesh was considered. The pelvis was embedded and symmetry conditions were applied to the node of subcutaneous fat mesh located in the symmetry plane. Nodes on upper and lower surfaces of the subcutaneous fat were fixed to zero in vertical direction. For the lower extremity of the three glutei muscles, vertical degree of freedom of each node was coupled to avoid local distortion of the mesh during loading (Figure 3).

A rigid plate was created on the side of the model, close to the most lateral node of the skin and parallel to the symmetry plane of the model. This rigid plate can only move in direction along its normal. A sliding contact between the skin and the rigid plate was defined with a coefficient of friction equal to 0.2 with a Coulomb friction model.

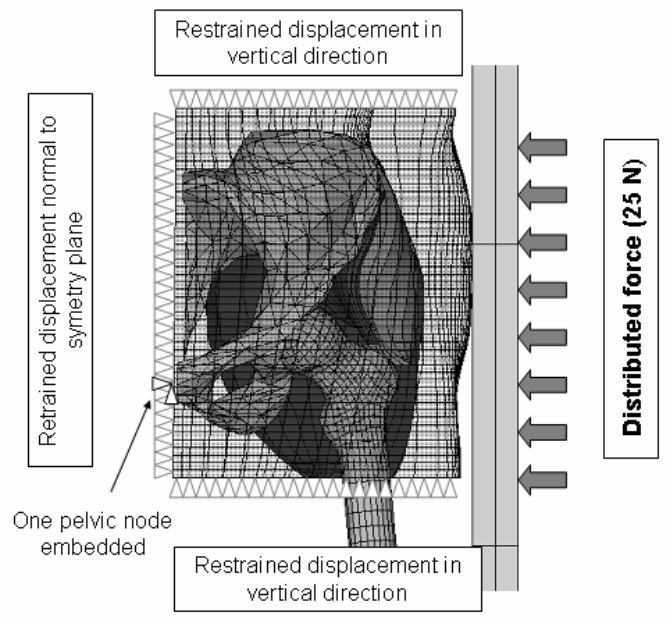

Figure 3. Boundary conditions applied on the mesh

The volume of each gluteus muscle, the horizontal distance between great trochanter and the rigid plate and the thickness of soft tissue thickness covering the great trochanter were also calculated for the mesh. The goal of the preliminary simulation was to verify the coherence of the model response. A distributed load of 25 $\mathrm{N}$ was applied to the most lateral surface of the rigid plate to simulate a lateral 
compression of soft tissue. So, the displacement of the rigid plate and the maximal hydrostatic pressure within soft tissue were analyzed after the simulation on order to evaluate the soft tissue deformation. The maximal Von Mises stress within proximal femur was computed (Duchemin et al., 2007a; Duchemin et al., 2007b).

\section{Results}

The patient-specific model of the hip with soft tissue was generated for the ten patients and it was composed of 29502 to 36559 elements with 16352 to 27531 nodes. For the ten models, all the elements respect quality criteria after the automatic mesh procedure.

In this methodological paper, we focused the results analysis on the representative subject. The volume of the three glutei muscles, the thickness of soft tissue covering the hip and the distance from rigid plate to great trochanter in the initial configuration are detailed in Table 2.

Table 2. Simulation's results: muscle volumes, soft tissue thickness covering the great trochanter, horizontal distance between great trochanter and the rigid plate were calculated from the mesh. At the end of simulation, rigid plate displacement, maximal hydrostatic pressure within soft tissue and maximal Von Mises stress within proximal femur were assessed

\begin{tabular}{|c|c|c|}
\hline $\begin{array}{l}\text { Muscle volume } \\
\qquad\left(\mathrm{cm}^{3}\right)\end{array}$ & $\begin{array}{l}\text { Gluteus maximus } \\
\text { Gluteus medius } \\
\text { Gluteus minimus }\end{array}$ & $\begin{array}{c}474 \\
276 \\
82 \\
\end{array}$ \\
\hline \multicolumn{2}{|c|}{$\begin{array}{l}\text { Soft tissue thickness } \\
\qquad(\mathrm{mm})\end{array}$} & 35.8 \\
\hline \multicolumn{2}{|c|}{$\begin{array}{l}\text { Distance great trochanter to rigid plate } \\
\qquad(\mathrm{mm})\end{array}$} & 40.3 \\
\hline \multicolumn{2}{|c|}{$\begin{array}{l}\text { Rigid plate displacement } \\
(\mathrm{mm})\end{array}$} & 33.2 \\
\hline \multicolumn{2}{|c|}{$\begin{array}{l}\text { Max. hydrostatic pressure } \\
(\mathrm{kPa})\end{array}$} & 9.3 \\
\hline Max. von Mises & $\begin{array}{l}\text { ress within femur } \\
\text { a) }\end{array}$ & 366 \\
\hline
\end{tabular}

Soft tissues thickness covering the hip was $35.8 \mathrm{~mm}$ and the rigid plate was initially located at $40.3 \mathrm{~mm}$ for the great trochanter. Maximal Von Mises stress was equal to $366 \mathrm{kPa}$ and was localized in the cortical bone of the femoral neck near the junction with femoral head. The maximal hydrostatic pressure was localized within subcutaneous fat, at the interface with the great trochanter of the femur. Its value was $9.3 \mathrm{kPa}$. The Figure 2 illustrates the deformed shape of the model with a load of $25 \mathrm{~N}$ 
distributed on the external face of the rigid plate. The Von Mises stress distribution in the proximal femur is presented on the Figure 4.
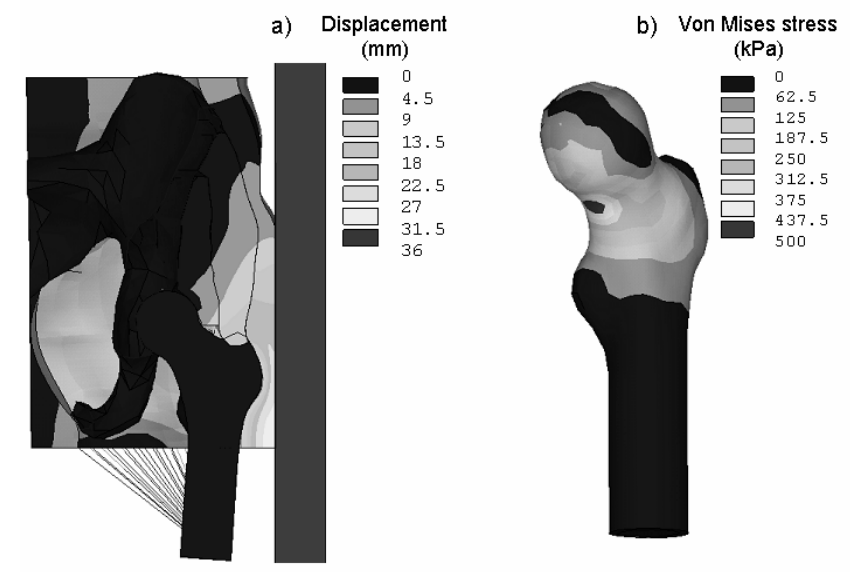

Figure 4. Results: a) Vector norm of translation in deformed station frontal cut view b) repartition of Von Mises stress within proximal femur

\section{Discussion}

The first difficulty when considering musculoskeletal finite element model is the generation of soft tissue reconstruction and mesh. Indeed, muscle segmentation is more difficult than bone segmentation since distinction between individual muscles is often difficult or impossible to assess, making automatic contour detection unsuitable. Therefore, muscle geometry is usually obtained with a manual contouring on axial slices (Jaegers et al., 1992). However, manual muscle contouring is time consuming and limits the number of subject to only one model (Behr et al., 2006; Blemker et al., 2005; Blemker et al., 2006). The method developed to generate muscles meshes reduce the time of process, comparing to muscular models obtained from systematic manual contouring on each images (Behr et al., 2006; Blemker et al., 2005; Ejima et al., 2005). An evaluation of volume difference between the two methods was previously performed and results have shown a good agreement (Jolivet et al., 2006). Thus this patient-specific finite element model of the hip is the first model which includes soft tissue composed of glutei muscles and subcutaneous fat.

Although this patient-specific model considers muscles and subcutaneous fat, several limitations had to be dealt with. First, in the context of osteoporotic hip fracture, cortical thickness repartition and bone material properties are determinant (Silva, 2007). In this study, cortical thickness was not personalized because the major aim was to assess the soft tissue effect on femur stress distribution apart from the changes in bone material properties. However, cortical thickness and bone materials properties can be extracted 
from CT-scan images and integrated into the femur model (Duchemin et al., 2007b; Majumder et al., 2007). Although bone tissue was known to show a high degree of anisotropy associated with a non linear relation between stress and strain, models considering isotropic material bone could be sufficient to represent the mechanical response of the proximal femur (Couteau et al., 1998; Lengsfeld et al., 1998). Thus, Von Mises stress, in combination with ultimate stress derived from CT-scan data, could be employed as failure criterion assuming that fracture occurs with damage accumulations and considering the expand of contiguous failure elements (Duchemin et al., 2007b).

Secondly, the formulation of constitutive material law for muscle and fat tissue is limited to the availability of experimental data. Untaroiu et al. determined the value of Mooney Rivlin coefficients with unconfined compression on cadaveric samples invitro (Untaroiu et al., 2005). Soft tissue material was assumed to be isotropic. This hypothesis is consistent for fat tissue whereas fiber architecture within muscle introduces anisotropy of the mechanical behavior of muscle tissue. However, in case of compression transversally to fiber orientation, the hypothesis of isotropic can be assumed (Untaroiu et al., 2005; Weiss et al., 1996).

Third, boundary conditions were essentials to consider in this body segment model. To preserve to confinement of soft tissue and because this simulation was realized in quasi-static state, displacement of soft tissue was restrained in vertical direction. Relative muscles and fat movement was arbitrary tied or sliding without friction under anatomical consideration. Fascias and aponeurosis, which divide into compartments soft tissue and muscle of the hip could be implemented in future developments

Another limitation regards the muscle tonicity which was not included in this model whereas muscle activity modifies the apparent stiffness of muscle tissue and causes an increase in the rigidity of the trunk, the pelvis and lower limbs. Muscular contraction was reported to increase and even double the peak force transmitted to femur (Robinovitch et al., 1991). In the current study, muscles were meshed independently in the model in order to allow for future developments towards modeling of muscle activation through fiber insertion and contraction and an adapted constitutive law with the active state of muscle could be implemented provided the fiber direction was determined for muscles (Blemker et al., 2006; Johansson et al., 2000; Jolivet et al., 2001; Teran et al., 2005).

Despite those limitations and even if the simulation of soft tissue lateral compression was realized in quasi-static state, results permitted to verify qualitatively the coherence of the model in the context of hip fracture due to a fall of the subject. Localization of the maximal stress within femur in the femoral neck was in agreement with clinical observations on hip fracture location (Marks et al., 2003). Moreover, The localization of the maximal hydrostatic pressure in soft tissue corresponded to the localization a subcutaneous hematoma systematically observed on the great trochanter on patient suffering hip fracture resulting from a fall (Parkkari et al., 1999).

At this time, only one study focused on the influence of soft tissue covering the hip on stress distribution within the proximal femur during the impact phase with a finite 
element model (Majumder et al., 2007).This model considered only one subject with no distinction between fat and muscle and no separation of muscles between each other which makes difficult to analyze the role of each muscle in future evolutions to take into account muscle activation during impact.

In conclusion, an original methodology was presented to generate patient-specific finite element model. The feasibility of the approach was confirmed and preliminary evaluation demonstrated the potential clinical relevance of such a modeling. The patient-specific modeling of the hip included muscles and subcutaneous fat. This approach could be useful to biomechanical analysis for exploring potential risk factors associated with soft tissue in hip fracture risk.

\section{References}

Behr M., Arnoux P. J., Serre T., Thollon L., Brunet C., "Tonic finite element model of the lower limb", J. Biomech Eng, vol. 128, n 2, 2006, p. 223-228.

Besnault B., Guillemot H., Robin S., Lavaste F., Le Coz J. Y., “A 3D Viscoelastic Finite Element Model of The Human Pelvis", Proceedings of the XXIV Congrès de la Société de Biomécanique, Beaune, France 15-17 septembre, 1999.

Blemker S.S., Delp S. L., “Three-dimensional representation of complex muscle architectures and geometries", Ann Biomed Eng, vol. 33, n 5, 2005, p. 661-673.

Blemker S.S., Delp S.L., "Rectus femoris and vastus intermedius fiber excursions predicted by three-dimensional muscle models", J. Biomech, vol. 39, n 8, 2006, p. 1383-1391.

Bouxsein M. L., Szulc P., Munoz F., Thrall E., Sornay-Rendu E., Delmas P. D., "Contribution of trochanteric soft tissues to fall force estimates, the factor of risk, and prediction of hip fracture risk", J. Bone Miner Res, vol. 22, n 6, 2007, p. 825-831.

Cody D. D., Hou F. J., Divine G. W., Fyhrie D. P., "Femoral structure and stiffness in patients with femoral neck fracture", J. Orthop Res, vol. 18, n³, 2000, p. 443-448.

Couteau B., Hobatho M. C., Darmana R., Brignola J. C., Arlaud J. Y., "Finite element modelling of the vibrational behaviour of the human femur using CT-based individualized geometrical and material properties", J. Biomech, vol. 31, n 4, 1998, p. 383-386.

Cummings S. R., Nevitt M. C., "Non-skeletal determinants of fractures: the potential importance of the mechanics of falls. Study of Osteoporotic Fractures Research Group", Osteoporos Int, vol. 4, Suppl. 1, 1994, p. 67-70.

De Laet C. E., van Hout B. A., Burger H., Hofman A., Pols H. A., "Bone density and risk of hip fracture in men and women: cross sectional analysis”, $B M J$, vol. 315, n 7102,1997 , p. 221-225.

Diridollou S., Black D., Lagarde J. M., Gall Y., Berson M., Vabre V., Patat F., Vaillant L., "Sex- and site-dependent variations in the thickness and mechanical properties of human skin in vivo", Int J. Cosmet Sci, vol. 22, n 6, 2000, p. 421-435. 
Dreux C., Delmas P. D., « Les méthodes de mesure de la densité minérale osseuse (DMO) et des marqueurs du remodelage osseux dans le dépistage de l'ostéoporose. », Bull Acad Nat Med, vol. 185, n 8, 2001, p. S169.

Duchemin L., Bousson V., Raossanaly C., C. B., Laredo J., W. S. Mitton D., "Prediction of mechanical properties of cortical bone by quantitative computed tomography", Med Eng Phys, doi:10.1016/j.medengphy.2007.04.008, 2007a.

Duchemin L., Mitton D., Jolivet E., Bousson V., Laredo J. D., Skalli W., “An anatomical subject-specific FE-model for hip fracture load prediction”, Comput Methods Biomech Biomed Engin, doi: 10.1080/10255840701535965, $2007 \mathrm{~b}$.

Ejima S., Ono K., Kaneoka K., Fukushima M., "Development and validation of the human neck muscle model under impact loading", Proceedings of the IRCOBI, Prague,Czech Republic, 2005.

Hayes W. C., Myers E. R., Morris J. N., Gerhart T. N., Yett H. S., Lipsitz L. A., "Impact near the hip dominates fracture risk in elderly nursing home residents who fall", Calcif Tissue Int, vol. 52, $\mathrm{n}^{\circ} 3,1993$, p. 192-198.

Hendriks F. M., Brokken D., van Eemeren J. T., Oomens C. W., Baaijens F. P., Horsten J. B., "A numerical-experimental method to characterize the non-linear mechanical behaviour of human skin”, Skin Res Technol, vol. 9, n³, 2003, p. 274-283.

Jaegers S., Dantuma R., de Jongh H. J., "Three-dimensional reconstruction of the hip muscles on the basis of magnetic resonance images", Surg Radiol Anat, vol. 14, n 3, 1992, p. 241-249.

Johansson T., Meier P. Blickhan R., “A finite-element model for the mechanical analysis of skeletal muscles”, J. Theor Biol, vol. 206, n 1, 2000, p. 131-149.

Jolivet E., Daguet E., Pomero V., Bonneau D., Laredo J. D., Skalli W., "Volumic patientspecific reconstruction of muscular system based on a reduced dataset of medical images", Proceedings of the $7^{\text {th }}$ International Symposium on computer methods in biomechanics and biomedical engineering, Antibes, 22-25 mars, 2006.

Jolivet E., Pomero V., Skalli W., "Finite Element Modelling of Muscle", Proceedings of the $5^{\text {th }}$ International Symposium on Computer Methods in Biomechanics and Biomedical Engineering, Italy, Rome, 31October-3 November, 2001.

Keyak J. H., Rossi S. A., Jones K. A., Skinner H. B., "Prediction of femoral fracture load using automated finite element modelling”, J. Biomech, vol. 31, n 2, 1998, p. 125-133.

Lafage V., Laporte S., Dubousset J., Lavaste F., Skalli W., "Personalized Finite Element Mesh of Human Body Stucture Using 3D Reconstruction and Kriging Technique", Proceedings of the XVIII ${ }^{\text {th }}$ Congress of the International Society of Biomechanics, Zurich, Suisse, 2001.

Lavaste F., Skalli W., Robin S., Roy-Camille R. Mazel C., “Three-dimensional geometrical and mechanical modelling of the lumbar spine”, J. Biomech, vol. 25, n 10, 1992, p. 1153-1164. 
Lengsfeld M., Schmitt J., Alter P., Kaminsky J., Leppek R., “Comparison of geometry-based and CT voxel-based finite element modelling and experimental validation", Med Eng Phys, vol. $20, \mathrm{n}^{\circ} 7,1998$, p. 515-522.

Lotz J. C., Hayes W. C., "The use of quantitative computed tomography to estimate risk of fracture of the hip from falls", J. Bone Joint Surg Am, vol. 72, n 5, 1990, p. 689-700.

Majumder S., Roychowdhury A., Pal S., "Simulation of hip fracture in sideways fall using a 3D finite element model of pelvis-femur-soft tissue complex with simplified representation of whole body", Med Eng Phys, vol. 29, n 10, 2007, p. 1167-1178.

Marks R., Allegrante J. P., Ronald MacKenzie C., Lane J. M., "Hip fractures among the elderly: causes, consequences and control”, Ageing Res Rev, vol. 2, n 1, 2003, p. 57-93.

Parkkari J., Kannus P., Palvanen M., Natri A., Vainio J., Aho H., Vuori I., Jarvinen M., "Majority of hip fractures occur as a result of a fall and impact on the greater trochanter of the femur: a prospective controlled hip fracture study with 206 consecutive patients", Calcif Tissue Int, vol. 65, $\mathrm{n}^{\circ} 3,1999$, p. 183-187.

Robinovitch S. N., Hayes W. C., McMahon T. A., "Prediction of femoral impact forces in falls on the hip", J. Biomech Eng, vol. 113, n 4, 1991, p. 366-374.

Schuit S. C., van der Klift M., Weel A. E., de Laet C. E., Burger H., Seeman E., Hofman A., Uitterlinden A. G., van Leeuwen J. P. Pols H. A., "Fracture incidence and association with bone mineral density in elderly men and women: the Rotterdam Study", Bone, vol. 34, n 1 , 2004, p. 195-202.

Silva M. J., "Biomechanics of osteoporotic fractures”, Injury, vol. 38, Suppl 3, 2007, p. S69-76.

Teran J., Sifakis E., Blemker S. S., Ng-Thow-Hing V., Lau C. Fedkiw R., "Creating and simulating skeletal muscle from the visible human data set", IEEE Transactions on Visualization and Computer Graphics, vol. 11, n 3, 2005, p. 317-328.

Trochu F., “A contouring program based on dual kriging interpolation”, Eng comput., vol. 9, $\mathrm{n}^{\circ} 3,1993$, p. 160-177.

Untaroiu C., Darvish K., Crandall J., Deng B., Wang J., "Characterization of the lower limb soft tissues in pedestrian finite element models", Proceedings of the $19^{\text {th }}$ international technical conference on the enhanced safety of vehicules, Washington DC, 2005.

van Donkelaar C. C., Drost M. R., van Mameren H., Tuinenburg C. F., Janssen J. D., Huson A., "Three-dimensional reconstruction of the rat triceps surae muscle and finite element mesh generation of the gastrocnemius medialis muscle", Eur J. Morphol, vol. 34, n 1, 1996, p. 31-37.

Weiss J. A., Maker B. N., Govindjee S., "Finite element implentation of incompressible, transversaly isotropic hyperelasticity”, Comput. Methods. Appl. Mech. Engrg, vol. 135, $\mathrm{n}^{\circ} 1-2,1996$, p. 107-128. 
